\title{
SLC35B2 Expression is Associated with a Poor Prognosis of Invasive Ductal Breast Carcinoma
}

\author{
Anongruk Chim-ong ${ }^{1}$, Charin Thawornkuno1, Porntip Chavalitshewinkoon- \\ Petmitr $^{2}$, Phaibul Punyarit ${ }^{3}$, Songsak Petmitr ${ }^{1 *}$
}

\begin{abstract}
Background: Breast cancer is the most common malignancy in women worldwide, including Thailand, and is a major cause of mortality and morbidity, despite advances in diagnosis and treatment. Novel gene expression in breast cancer is a focus in searches for prognostic biomarkers and new therapeutic targets. Materials and Methods: The mRNA expression of novel B4GALT4, SLC35B2, and WDHD1 genes in breast cancer were examined in invasive ductal breast carcinoma (IDC) patients using quantitative real-time reverse transcription polymerase chain reaction (QRT-PCR). Results: Among these genes, increased expression of SLC35B2 mRNA was significantly associated with TNM stage III + IV of IDC (p<0.001). Hence, up-regulation of $S L C 35 B 2$ may serve as a prognostic biomarker for poor prognosis, and is also a potential therapeutic target in breast cancer.
\end{abstract}

Keywords: Invasive ductal breast carcinoma - poor prognosis - SLC35B2

Asian Pac J Cancer Prev, 15 (15), 6065-6070

\section{Introduction}

Breast carcinomas are highly heterogeneous in their morphology, biology, response to therapy and clinical course. They are the most common cancers among women in Thailand (Khuhaprema et al., 2006). The trend in incidence rate of Thai women breast cancer continues to increase over time, especially in the central region (Sriplung et al., 2006), although the other country in mainland South-East Asia has a relatively low (Moore et al., 2008). The incidence of breast cancer in Thailand is $30.7 / 100,000 /$ year and the death rate is $10.8 / 100,000 /$ year (Ferlay et al., 2010). Thai women who have a relatively high incidence were at age of 40 years and older (Kotepui and Chupeerach, 2013) and who have lifetime occupation in an industrial (Ekpanyaskul et al., 2010). The most common pathological type of Thai breast cancer is invasive ductal carcinoma (Khuhaprema et al., 2010) with the luminal-A subtype (Chuthapisith et al., 2012).

The prognosis for breast cancer depends on its stage, typically defined as stage I to IV, with sub-stages (Taneja et al., 2010). The complexity and heterogeneity of carcinogenesis is also due to the activation of oncogenes, loss of function of tumor suppressor genes, and disregulation of crucial cell-signaling cascades responsible for cell growth, differentiation, communication, and apoptosis (Pakkiri et al., 2009). Several genetic alterations are reportedly biomarkers for prognosis of sporadic breast cancer, including ERBB2 (HER2/neu), MYC, and CCND1 (Cyclin D1) (Kenemans et al., 2008). Over-expression of $E R B B 2$ was associated with more aggressive breastcancer characteristics (Blackwell et al., 2010) and was also used as a target for breast-cancer therapy (Yu and Hung, 2000). MYC amplification has been associated with poor prognosis, and is involved with ERBB2 amplification (Nair et al., 2013). Breast-cancer patients with $M Y C /$ $E R B B 2$ co-amplification had a worse prognosis than patients who had amplified levels of only one of these (AlKuraya et al., 2004). High levels of CCND1 expression have been associated with poor prognosis, particularly in ER-positive tumors, and also influenced therapeutic decisions in ER-positive breast cancer patients (Eeckhoute et al., 2006). Careful evaluation of these biomarkers with current treatment modality is required for determination. However, different breast cancer pathways emerge early in the process of oncogenesis, leading to clinically different tumor types. Therefore, it is necessary to identify novel prognostic and predictive biomarkers for breast tumors; this remains a long-awaited priority to enhance treatment.

A previous study of the gene expression profiles of Thai sporadic-breast-cancer patients indicated that the over-expression of 3 genes--UDP-Gal:betaGlcNAc beta 1,4-galactosyltransferase, polypeptide 4 (B4GALT4); solute carrier family 35 (adenosine 3'-phospho 5'-phosphosulfate transporter 1) number B2 (SLC35B2) and WD repeat and HMG-box DNA binding protein

${ }^{1}$ Department of Molecular Tropical Medicine and Genetics, ${ }^{2}$ Department of Protozoology, Faculty of Tropical Medicine, Mahidol University, ${ }^{3}$ Army Institute of Pathology, Phramongkutklao Medical Center, Ratchawithi Road, Bangkok, Thailand *For correspondence: songsak.pet@mahidol.ac.th 
1 (WDHD1)--was associated with advanced stages of IDC (Arnutti et al., 2013). In this study, the differential expressions of these mRNAs in IDC were verified by QRT-PCR. The association between the expression of these mRNAs and clinical outcomes was evaluated.

\section{Materials and Methods}

\section{Patients and clinical features}

A total of 35 fresh breast carcinomas and their corresponding normal tissues were obtained from the Pathology Division, Army Institute of Pathology, Phramongkutklao Medical Center, Bangkok, Thailand, between the years 2006 and 2010. No cancer patients had undergone chemotherapy or radiation before undergoing surgery. This study was approved by the Ethics Committee of the Faculty of Tropical Medicine, Mahidol University, Bangkok, Thailand (MUTM 2013-029-01).

\section{Sample processing}

After resection, tissue samples were snap-frozen in TRIzol $^{\circledR}$ reagent (Invitrogen, CA, USA) and stored at $-80^{\circ} \mathrm{C}$ until use. All tumor tissue sections were stained with hematoxylin and eosin, and were then analyzed by an experienced breast pathologist. Eligible samples contained $>90 \%$ tumor cells. Total RNA was isolated by TRIzol® reagent (Invitrogen, USA) according to the manufacturer's instructions. The total amount of RNA isolated was quantified using a Nanodrop 1000 spectrophotometer (Thermo Fisher Scientific, USA) $\mathrm{OD}_{260}$ measurements, and its quality evaluated by visualizing specific bands (18S and 28S rRNA) using 1.5\% gel electrophoresis. Firststrand cDNA was performed using Superscript ${ }^{\circledR}$ VILO $^{\mathrm{TM}}$ cDNA Synthesis kits (Invitrogen, USA) and purified by DNAclear $^{\mathrm{TM}}$ cDNA Purification Kit (Applied Biosystems, USA). The quantity of purified cDNA was measured by Nanodrop 1000 spectrophotometer and qualified using conventional PCR with $\beta$-actin primer. mRNA expression in each sample was measured by QRT-PCR.

\section{Quantitative real-time reverse transcription polymerase chain reaction}

Primers were designed by Primer-BLAST program (NCBI) using nucleotide sequences from the NCBI database. The nucleotide sequences of all primers are shown in Table 1. The QRT-PCR analysis was performed with LightCycler ${ }^{\circledR}$ FastStart DNA Master SYBR Green I (Roach, Germany). Each $20 \mu$ of reaction mixture contained $2 \mu \mathrm{l}$ of $10 \mathrm{X}$ LightCycler ${ }^{\circledR}$ FastStart DNA
Master SYBR Green I, $1 \mu \mathrm{l}$ of $5 \mu \mathrm{M}$ forward primer, 1 $\mu \mathrm{l}$ of $5 \mu \mathrm{M}$ reverse primer, $1.6 \mu \mathrm{l}$ of $25 \mathrm{mM} \mathrm{MgCl}_{2}, 12.4$ $\mu \mathrm{l}$ of sterile distilled water and $2 \mu \mathrm{l}$ of $10 \mathrm{ng}$ cDNA. The reactions were carried out using a Roche Lightcycler ${ }^{\circledR}$ 2.0 Real-Time PCR system (Roche, Germany), with the following cycling conditions: pre-incubation at $95^{\circ} \mathrm{C}$ for 10 minutes, followed by 45 cycles of denaturation at $95^{\circ} \mathrm{C}$ for 10 seconds, annealing temperature (specific to the primer) for 5 seconds, and extension at $72^{\circ} \mathrm{C}$ for 20 second.

\section{Analysis of gene expression using the $2^{-\triangle \Delta C T}$ method}

The $2^{-\Delta \Delta \mathrm{CT}}$ method was used to calculate relative quantification in gene expression determined by QRTPCR, according to a previously described method (Ginzinger, 2002). The $2^{-\Delta \Delta C T}$ method was used to calculate relative changes in gene expression determined from QRT-PCR experiments. In this study, data were presented as fold-change in target genes B4GALT4, SLC 35B2, and $W D H D 1$ expression in tumors normalized to the internal control gene ( $\beta$-actin) and relative to the normal control (matched with normal as a calibrator). Over-expression of mRNA was specified as $\mathrm{N}$-fold change $\geq 2.0$, normal mRNA expression was specified as $\mathrm{N}$-fold change (range 0.5001-1.9999), and under-expression was specified as $\mathrm{N}$-fold change $\leq 0.5$. All samples were screened at least twice.

\section{Statistical analysis}

Categorical data were expressed as frequency (percentage) and continuous data as mean \pm SD. Associations between mRNA expression and several clinic-pathological parameters, i.e., age, tumor-nodemetastasis (TNM) stage, and triple-negative breast cancer (TNBC) status were analyzed using univariate logistic regression. Statistical analysis was performed using SPSS version 11.5 (SPSS Inc., Chicago, IL, USA), and a p value of $<0.05$ was considered statistically significant.

\section{Results}

\section{Clinical characteristics of the patients}

Thirty-five invasive ductal carcinoma cases were initially collected for study in this investigation. The clinical outcomes of the patients and the expression profiles of $3 \mathrm{mRNAs}$ are presented in Table 2. The median age of all cases was 57 (range 34-91) years. Twelve cases $(34 \%)$ were aged $\leq 50$ years and $23(66 \%)>50$ years. The TNM staging system, based on The American Joint

Table 1. Primer Sequences Used for QRT-PCR Amplification

\begin{tabular}{lclc}
\hline Gene & Location & Primer sequence (5'-3') & Product size (bp) \\
\hline$\beta$-actin & $7 \mathrm{p} 22$ & F: TCACCCACACTGTGCCCATCTACGA & 295 \\
& & R: CAGCGGAACCGCTCATTGCCAATGG & 141 \\
B4GALT4 & $3 \mathrm{q} 13.3$ & F: CATCCCAAGCATCTGGTGGT & 141 \\
& & R: TCCCCATCCCCAGTAGTTGT & 143 \\
SLC35B2 & F: ACAGGGCTCCAGGTGTCTTATC & \\
& & R: TGCCAGCACTCGGTTCATTAGC & \\
& & F: TCCGTTGTGTGGAACTTGCT & \\
\hline
\end{tabular}

$\mathrm{F}=$ forward, $\mathrm{R}=$ reverse, $\mathrm{bp}=$ base pair 
Table 2. Clinicopathological Parameters and mRNA Expression Patterns of B4GALT4, SLC35B2 and WDHD1 of Intraductal Breast Carcinoma Patients

\begin{tabular}{|c|c|c|c|c|c|c|}
\hline \multirow[t]{2}{*}{ No. } & \multirow[t]{2}{*}{ Age } & \multirow{2}{*}{$\begin{array}{l}\text { TNM } \\
\text { stage* }\end{array}$} & \multirow[t]{2}{*}{$\mathrm{TNBC}^{* * *}$} & \multicolumn{3}{|c|}{ mRNA expression patterns*** } \\
\hline & & & & B4GALT4 & $S L C 35 B 2$ & WDHD1 \\
\hline 1 & 76 & IIIA & - & - & + & - \\
\hline 2 & 80 & II & - & - & $\mathrm{n}$ & TUD \\
\hline 3 & 70 & IIIC & - & NUD & + & - \\
\hline 4 & 45 & IIA & - & - & - & $\mathrm{n}$ \\
\hline 5 & 53 & I & - & $\mathrm{n}$ & - & + \\
\hline 6 & 54 & IIB & - & + & + & TUD \\
\hline 7 & 83 & IIB & - & NUD & + & - \\
\hline 8 & 37 & II & - & + & $\mathrm{n}$ & - \\
\hline 9 & 91 & I & - & NUD & + & TUD \\
\hline 10 & 44 & IIIA & - & $\mathrm{n}$ & + & NUD \\
\hline 11 & 41 & IIB & - & $\mathrm{n}$ & - & NUD \\
\hline 12 & 38 & IIIC & + & TUD & + & - \\
\hline 13 & 68 & IIA & + & $\mathrm{n}$ & + & TUD \\
\hline 14 & 54 & IIA & - & NUD & $\mathrm{n}$ & - \\
\hline 15 & 48 & IIB & + & NUD & + & - \\
\hline 16 & 59 & IIB & - & $\mathrm{n}$ & + & - \\
\hline 17 & 44 & IIA & - & NUD & $\mathrm{n}$ & - \\
\hline 18 & 65 & II & - & + & $\mathrm{n}$ & TUD \\
\hline 19 & 51 & I & - & - & $\mathrm{n}$ & NUD \\
\hline 20 & 71 & I & - & $\mathrm{n}$ & $\mathrm{n}$ & TUD \\
\hline 21 & 39 & I & - & NUD & $\mathrm{n}$ & $\mathrm{n}$ \\
\hline 22 & 45 & IIIA & - & + & + & NUD \\
\hline 23 & 52 & I & - & $\mathrm{n}$ & $n$ & - \\
\hline 24 & 66 & IIIA & - & $\mathrm{n}$ & + & $\mathrm{n}$ \\
\hline 25 & 58 & IIIB & - & - & + & NUD \\
\hline 26 & 78 & IIA & + & + & $\mathrm{n}$ & NUD \\
\hline 27 & 39 & I & - & NUD & - & $\mathrm{n}$ \\
\hline 28 & 67 & IIB & - & $\mathrm{n}$ & $\mathrm{n}$ & + \\
\hline 29 & 54 & IIB & - & $\mathrm{n}$ & $\mathrm{n}$ & $\mathrm{n}$ \\
\hline 30 & 46 & IA & + & $\mathrm{n}$ & + & - \\
\hline 31 & 69 & II & - & $\mathrm{n}$ & $\mathrm{n}$ & TUD \\
\hline 32 & 34 & IIIA & - & $\mathrm{n}$ & + & - \\
\hline 33 & 59 & IIA & - & NUD & + & - \\
\hline 34 & 61 & I & - & - & $\mathrm{n}$ & - \\
\hline 35 & 60 & IIIA & - & $\mathrm{n}$ & + & NUD \\
\hline
\end{tabular}

*TNM stage $=$ tumor-node-metastasis stage $; *$ TNBC $=$ triple-negative breast cancer (Estrogen receptor, Progesterone receptor, Human epidermal growth factor receptor 2) (+ triple negative, - non-triple negative); $* * *$ mRNA expression pattern $(+=$ increased,$-=$ decreased, $\mathrm{n}=$ normal, TUD $=$ tumor undetectable, NUD $=$ normal undetectable at 45 cycles of QRT-PCR)
Committee on Cancer (AJCC) system, identified 26 (74\%) patients with TNM stage I and II tumors, and $9(26 \%)$ with TNM stage III and IV. The percentages of patients with non-triple negative and triple-negative breast cancer were $86 \%$ (30 cases) and 14\% (5 cases), respectively.

\section{Differential gene expression}

QRT-PCR SYBR Green based dye I detection was performed to determine the mRNA signatures for these 3 genes in the 35 tumor sample and their normal counterparts, using the $\beta$-actin gene as an endogenous reference gene. Differences in B4GALT4, SLC35B2, and $W D H D 1$ gene expression correlated with TNM stage. The results indicated that increase of B4GALT4, SLC35B2 and WDHD1 mRNA expression was observed in 5 of 35 cases (14\%), 17 of 35 cases (49\%) and 2 cases (6\%), respectively. Notably, the over-expression of SLC35B2 was observed in all the patient with TMN stage III+IV (9 cases), while 8 of 26 cases with stage I+II harbored up regulation of this gene (Figure 1). Likewise, the clinical data indicated that 4 patients present tumor staging IIB while the other 4 case harbored stage I+IIA with triple negative characteristic. Univariate logistic regression analysis showed that increased levels of $S L C 35 B 2 \mathrm{mRNA}$ expression correlated with TNM stage III+IV of IDC (P $<0.001$ ) (Table 3).

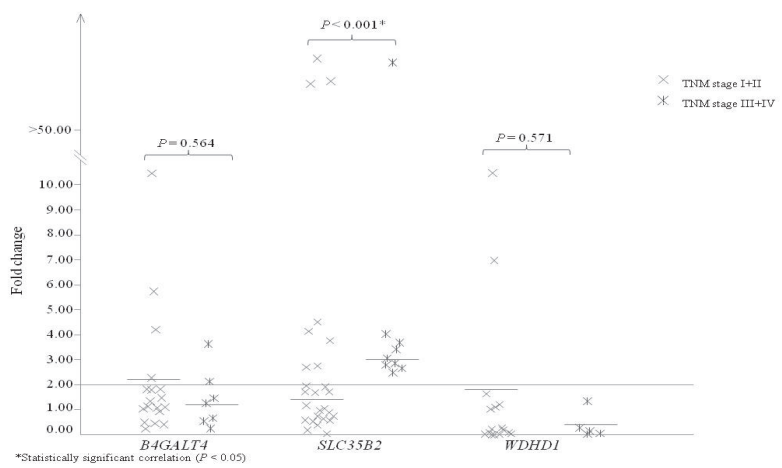

Figure 1.Differential Gene Expression of the Candidate Genes Correlated to the TNM Stage of Breast Cancer. Expression patterns of $B 4 G A L T 4, S L C 35 B 2$ and WDHD1 mRNA in IDC were diagnosed by QRT-PCR using $\beta$-actin mRNA as a internal control. The scatter plots was presented the $\mathrm{N}$-fold differential expression in the target gene correlated with TNM stage of IDC. The over-expression were defined by at least 2-fold

Table 3. Univariate Logistic Regression Analysis of B4GALT4, SLC35B2 and WDHD1 mRNA Expression and Clinicopathological Parameters in Breast Cancer

\begin{tabular}{|c|c|c|c|c|c|c|c|c|c|c|c|c|}
\hline \multirow[t]{2}{*}{ Parameters } & \multicolumn{4}{|c|}{$\begin{array}{c}\text { B4GALT4 } \\
\text { Increased mRNA expression }(\mathrm{n}=25) \\
\end{array}$} & \multicolumn{4}{|c|}{$\begin{array}{c}\text { SLC35B2 } \\
\text { Increased mRNA expression }(\mathrm{n}=35) \\
\end{array}$} & \multicolumn{4}{|c|}{$\begin{array}{c}\text { WDHD1 } \\
\text { Increased mRNA expression }(\mathrm{n}=21) \\
\end{array}$} \\
\hline & $\begin{array}{l}\text { Yes, } \\
\mathrm{n}(\%)\end{array}$ & $\begin{array}{l}\text { No, } \\
\mathrm{n}(\%)\end{array}$ & $\begin{array}{c}\mathrm{OR} \\
(95 \% \mathrm{CI})\end{array}$ & $\mathrm{p}$ value & $\begin{array}{l}\text { Yes, } \\
\mathrm{n}(\%)\end{array}$ & $\begin{array}{l}\text { No, } \\
\text { n }(\%)\end{array}$ & $\begin{array}{c}\mathrm{OR} \\
(95 \% \mathrm{CI})\end{array}$ & $\mathrm{p}$ value & $\begin{array}{l}\text { Yes, } \\
\mathrm{n}(\%)\end{array}$ & $\begin{array}{l}\text { No, } \\
\mathrm{n}(\%)\end{array}$ & $\begin{array}{c}\text { OR } \\
(95 \% \mathrm{CI})\end{array}$ & $\mathrm{p}$ value \\
\hline \multicolumn{13}{|c|}{ Age at diagnosis } \\
\hline$\leq 50$ & 2(29) & $5(71)$ & 2.000 & 0.436 & $6(50)$ & $6(50)$ & 1.091 & 0.592 & $0(0)$ & $9(100)$ & - & 0.314 \\
\hline$>50$ & $3(17)$ & $15(83)$ & $(0.256-15.623)$ & & $11(48)$ & $12(52)$ & $(0.270-4.408)$ & & $2(17)$ & $10(83)$ & & \\
\hline \multicolumn{13}{|l|}{ TNM stage } \\
\hline $\mathrm{I}+\mathrm{II}$ & $4(22)$ & $14(78)$ & 1.714 & 0.564 & $8(31)$ & $18(69)$ & - & $<0.001^{*}$ & $2(12)$ & $14(88)$ & - & 0.571 \\
\hline III+IV & $1(14)$ & $6(86)$ & $(0.157-18.726)$ & & $9(100)$ & $0(0)$ & & & $0(0)$ & $5(100)$ & & \\
\hline \multicolumn{13}{|l|}{ TNBC } \\
\hline - & $4(18)$ & $18(82)$ & 2.250 & 0.504 & $13(43)$ & $17(57)$ & 5.231 & 0.151 & $2(11)$ & $16(89)$ & - & 0.729 \\
\hline+ & $1(33)$ & $2(67)$ & $(0.162-31.329)$ & & $4(80)$ & $1(20)$ & $(0.521-52.551)$ & & $0(0)$ & $3(100)$ & & \\
\hline
\end{tabular}

*Statistically significant correlation $(\mathrm{p}<0.05)$;* $\mathrm{OR}=$ odds ratio; $\mathrm{CI}=$ confidence interval; TNM stage=tumor-node-metastasis stage; TNBC=triple-negative breast cancer $(+$ triple-negative, -nontriple negative) 


\section{Discussion}

Breast cancer is still a potentially detrimental or even fatal cancer among women, despite developments in therapeutic techniques. Early diagnosis and therapeutic treatment of breast cancer leads to reduced progression of disease and is associated with a lower rate of mortality (Berry et al., 2005). Conventional prognostic factors include axillary lymph node status, tumor size, hormone-receptor status (ER and PR), expression of HER-2, and histological grade (Fitzgibbons et al., 2000). Other clinicopathological parameters and new molecular markers are under investigation, to improve the predictability of clinical characteristics. Two of these factors, axillary lymph node status and tumor size, have been categories in the TNM staging system designated by the American Joint Committee on Cancer (AJCC) staging system (Singletary et al., 2002; Edge and Compton, 2010). The TNM staging system is an internationally accepted system used to determine disease stage, and is defined as tumor stages I through IV. Tumor stage provides information about the extent of disease, which is used to aid in personal prognosis and guide therapeutic decisions. Moreover, the TNM staging system provides a framework for reporting therapeutic outcomes and thereby permits the efficacy of new treatments to be assessed (Woodward et al., 2003). Chances of survival decrease for each successive stage of breast cancer. 88 percent of women diagnosed with stage I breast cancer survive at least five years beyond their diagnosis, whereas 5-year survival rates for stage II, III, and IV cancers are 60-80\%, 40-50\%, and $15 \%$, respectively (Reed et al., 2000; Frkovic-Grazio et al., 2002; Olivotto et al., 2003). In practically, expression of estrogen receptor (ER), progesterone receptor (PR) and HER-2 are used to identify aggressiveness of breast cancer. Over-expression of HER-2 is associated with advanced clinical stages, high rate of ER/PR double negative and poor survival in breast carcinomas (Jana et al., 2012; Liu et al., 2012). Moreover, the lacking of these three receptors is classified as triple-negative breast cancer (TNBC). The comparison of 7 years and 9 years diseasefree and overall survival rates between TNBC patients and non-TNBC patients reported that the TNBC are correlated with younger disease onset age, larger tumor size, higher rate of axillary lymph node positivity, and higher tumor histological grade (Li et al., 2013). Furthermore, The TNBC is linked with a poor clinical outcome, frequent relapses and metastasis (De Giorgi et al., 2007; IsmailKhan and Bui, 2010).

Improving the understanding of gene expression, profiling, and innovative molecular analysis technology, are all steps needed to identify predictive and prognostic genes, which could help characterize tumors and enable better-tailored therapies (de Snoo et al., 2009; Kuderer and Lyman, 2009). Many of the molecular markers studied have both prognostic and predictive values. Generally, the classical molecular markers consist of Ki67, ER, $P R$, and HER2, while novel molecular markers include p53, p14ARF, cyclin D1, cyclin E, TBX2/3, BRCA1/2, and $V E G F$ are involved with the development of human breast cancer (Taneja et al., 2010). Moreover, various gene such as KAII, KISS1 and EMSY have been reported for the correlation to poor prognosis of breast cancer (Zhang and Jin, 2010; Madjd et al., 2014) whereas, increase mRNA expression of LPHN3 and MMP13 were associated with axillary-node metastasis (Kotepui et al., 2013). The use of classical markers to predict patient survival and therapeutic response to breast cancer has been well established, and they continue to be used as useful laboratory tests. Although abundant genetic and phenotypic alterations have been reported in breast cancer, only a handful of these have been identified and brought to clinical studies.

The solute carrier family 35 (adenosine 3'-phospho 5 '-phosphosulfate transporter 1), member B2 gene (SLC35B2) located in 6p12.1-p11.2 and encodes the protein adenosine 3'-phospho 5'-phosphosulfate transporter 1 (PAPST1). The PAST1 protein is one of two putative PAPS transporters; another is PAST2 (SLC35B3). Its function is the transportation of 3'-phosphoadenosine 5'-phosphosulfate (PAPS) from the cytosol, where it is synthesized, by a bifunctional PAPS synthetase (Li et al., 1995), into the Golgi lumen (Kamiyama et al., 2003). Sulfation is essential for the post-translational alterations of glycoproteins, proteoglycans, and glycolipids required for normal growth and development. The PAPS or nucleotide sulfate is a universal sulfuryl donor for sulfation (Kamiyama et al., 2003). Sulfate is transferred from PAPS to a defined position on the sugar residue by sulfotransferases. Two PAPS transporter genes have been identified in both humans and Drosophila (Kamiyama et al., 2003; Luders et al., 2003; Goda et al., 2006). In Drosophila, these PAPS transporters are required for the sulfation of cellular proteins and normal development. In humans, both PAPST1 (SLC35B2) and PAPST2 (SLC35B3) are necessary for the sulfation of the 6-sulfolactosamine epitope in a human colorectal carcinoma cell line (Huopaniemi et al., 2004; Kamiyama et al., 2006). The SLC35B2 gene also plays an important role in cancer-cell proliferation, by controlling their sulfation status as part of a desmoplastic reaction to support cancer growth in colorectal cancers (Kamiyama et al., 2011). Furthermore, over-expression of PAPST 1 or PAPST 2 reduced radiation-induced apoptosis in human Burkitt's lymphoma cells (Nakayama et al., 2013). This study showed that increased levels of SLC35B2 mRNA in invasive ductal breast carcinomas are associated with advanced-stage breast cancer. Thus, SLC 35B2 could be involved with a poor prognosis in human breast cancer. In light of this, the role of $S L C 35 B 2$ deserves further study, to help determine the genetic factors affecting prognosis and treatment of IDC.

In summary, QRT-PCR was used to validate the prognostic gene profile in Thai breast-cancer patients obtained from microarray data. The results suggested that up-regulation of $S L C 35 B 2$ is associated with a poor prognosis among patients with invasive ductal breast carcinoma. Interestingly, this may be the first report of the increase in $S L C 35 B 2$ mRNA expression associated with a poor prognosis in breast cancer. Consequently, SLC35B2 may be a potential candidate prognostic biomarker in breast cancer patients, as well as a potentially selective 
therapeutic target. Further studies with larger sample sizes will increase the precision of the data.

\section{Acknowledgements}

This research was supported by Mahidol University (SP). The authors thank all the participants in this study. We also thank Mr. Paul Adams, Faculty of Tropical Medicine, Mahidol University, who kindly assisted by proofing and correcting the English language in the manuscript.

\section{References}

Arnutti P, Kotepui M, Asanprakit W, et al (2013). Determination of whole transcription profiles and specific pathways in invasive ductal breast carcinoma. Int J Clin Exp Pathol, 6, 1112-20.

Al-Kuraya K, Schraml P, Torhorst J, et al (2004). Prognostic relevance of gene amplifications and coamplifications in breast cancer. Cancer Res, 64, 8534-40.

Berry DA, Cronin KA, Plevritis SK, et al (2005). Effect of screening and adjuvant therapy on mortality from breast cancer. N Engl J Med, 353, 1784-92.

Blackwell KL, Burstein HJ, Storniolo AM, et al (2010). Randomized study of Lapatinib alone or in combination with trastuzumab in women with ErbB2-positive, trastuzumabrefractory metastatic breast cancer. J Clin Oncol, 28, 1124-30.

Chuthapisith S, Permsapaya W, Warnnissorn M, et al (2012). Breast cancer subtypes identified by the $E R$, PR and HER-2 status in Thai women. Asian Pac J Cancer Prev, 13, 459-62.

De Giorgi U, Rosti G, Frassineti L, et al (2007). High-dose chemotherapy for triple negative breast cancer. Ann Oncol, 18, 202-3.

de Snoo F, Bender R, Glas A, Rutgers E (2009). Gene expression profiling: decoding breast cancer. Surg Oncol, 18, 366-78.

Eeckhoute J, Carroll JS, Geistlinger TR, Torres-Arzayus MI, Brown M (2006). A cell-type specific transcriptional network required for estrogen regulation of cyclin $D 1$ and cell cycle progression in breast cancer. Genes Dev, 20, 2513-26.

Edge SB, Compton CC (2010). The American Joint Committee on Cancer: the 7th edition of the AJCC cancer staging manual and the future of TNM. Ann Surg Oncol, 17, 1471-4.

Ekpanyaskul C, Khuhaprema T, Wiangnon S, Sangrajrang S (2010). Case-control study of occupational categories and breast cancer risk in Thailand. Asian Pac J Cancer Prev, 11, 793-7.

Ferlay J, Shin HR, Bray F, et al (2010). Estimates of worldwide burden of cancer in 2008: GLOBOCAN 2008. Int J Cancer, 127, 2893-917.

Fitzgibbons PL, Page DL, Weaver D, et al (2000). Prognostic factors in breast cancer. college of american pathologists consensus statement 1999. Arch Pathol Lab Med, 124, 966-78.

Frkovic-Grazio S, Bracko M (2002). Long term prognostic value of Nottingham histological grade and its components in early (pT1N0M0) breast carcinoma. J Clin Pathol, 55, 88-92.

Ginzinger DG (2002). Gene quantification using real-time quantitative PCR: an emerging technology hits the mainstream. Exp Hematol, 30, 503-12.

Goda E, Kamiyama S, Uno T, et al (2006). Identification and characterization of a novel Drosophila 3'-phosphoadenosine 5'-phosphosulfate transporter. J Biol Chem, 281, 28508-17.

Huopaniemi L, Kolmer M, Niittymaki J, Pelto-Huikko M, Renkonen R (2004). Inflammation-induced transcriptional regulation of Golgi transporters required for the synthesis of sulfo sLex glycan epitopes. Glycobiology, 14, 1285-94.

Ismail-Khan R, Bui MM (2010). A review of triple-negative breast cancer. Cancer Control, 17, 173-6.

Jana D, Mandal S, Mukhopadhyay M, et al (2012). Prognostic significance of HER-2/neu and survival of breast cancer patients attending a specialized breast clinic in Kolkata, Eastern India. Asian Pac J Cancer Prev, 13, 3851-5.

Kamiyama S, Suda T, Ueda R, et al (2003). Molecular cloning and identification of 3'-phosphoadenosine 5'-phosphosulfate transporter. J Biol Chem, 278, 25958-63.

Kamiyama S, Sasaki N, Goda E, et al (2006). Molecular cloning and characterization of a novel 3'-phosphoadenosine 5'-phosphosulfate transporter, PAPST2. J Biol Chem, 281, 10945-53.

Kamiyama S, Ichimiya T, Ikehara Y, et al (2011). Expression and the role of 3'- phosphoadenosine 5'-phosphosulfate transporters in human colorectal carcinoma. Glycobiology, 21, 235-46.

Kenemans P, Verstraeten RA, Verheijen RH (2008). Oncogenic pathways in hereditary and sporadic breast cancer. Maturitas, 61, 141-50.

Khuhaprema T, Srivatanakul P, Sriplung H, et al (2006). Bangkok cancer registry. In 'Cancer in Thailand Vol. IV, 1998-2000' Bangkok Medical Publisher, Bangkok pp 7-21.

Khuhaprema T, Srivatanakul P, Sriplung H, et al (2010). Bangkok cancer registry. In 'Cancer in Thailand Vol. V, 2001-2003' Bangkok Medical Publisher, Bangkok pp 113-8.

Kotepui M, Chupeerach C (2013). Age distribution of breast cancer from a Thailand population-based cancer registry. Asian Pac J Cancer Prev, 14, 3815-17.

Kotepui M, Thawornkuno C, Chavalitshewinkoon-Petmitr P, Punyarit P, Petmitr S (2012). Quantitative real-time RTPCR of ITGA7, SVEP1, TNSI1, LPHN3, SEMA3G, KLB and $M M P 13$ mRNA expression in breast cancer. Asian Pac J Cancer Prev, 13, 5879-82.

Kuderer NM, Lyman GH (2009). Gene expression profile assays as predictors of distant recurrence-free survival in early-stage breast cancer. Cancer Invest, 27, 885-90.

Li CY, Zhang S, Zhang XB, et al (2013). Clinicopathological and prognostic characteristics of triple- negative breast cancer (TNBC) in Chinese patients: a retrospective study. Asian Pac J Cancer Prev, 14, 3779-84.

Li H, Deyrup A, Mensch JR Jr, et al (1995). The isolation and characterization of cDNA encoding the mouse bifunctional ATP sulfurylase-adenosine 5'-phosphosulfate kinase.J Biol Chem, 270, 29453-9.

Liu AN, Sun P, Liu JN, et al (2012). Clinicopathologic characteristics and prognostic factors in patients with operable HER-2 overexpressing breast cancer. Asian Pac J Cancer Prev, 13, 1197-201.

Luders F, Segawa H, Stein D, et al (2003). Slalom encodes an adenosine 3'-phosphate 5'-phosphosulfate transporter essential for development in drosophila. EMBO J, 22, 3635-44.

Moore MA, Attasara P, Khuhaprema T, et al (2008). Cancer epidemiology in mainland south-east asia-past, present and future. Asian Pac J Cancer Prev, 10, 67-80.

Madjd Z, Akbari ME, Zarnani AH, et al (2014). Expression of EMSY, a novel BRCA2-link protein, is associated with lymph node metastasis and increased tumor size in breast carcinomas. Asian Pac J Cancer Prev, 15, 1783-9.

Nair R, Roden DL, Teo WS, et al (2013). c-Myc and Her2 cooperate to drive a stem-like phenotype with poor prognosis in breast cancer. Oncogene, (Epub ahead of print).

Nakayama F, Umeda S, Ichimiya T, et al (2013). Sulfation of keratan sulfate proteoglycan reduces radiation-induced 
apoptosis in human Burkitt's lymphoma cell lines. FEBS Lett, 587, 231-7.

Olivotto IA, Chua B, Allan SJ, et al (2003). Long-term survival of patients with supraclavicular metastases at diagnosis of breast cancer. J Clin Oncol, 21, 851-4.

Pakkiri P, Lakhani SR, Smart CE (2009). Current and future approach to the pathologist's assessment for targeted therapy in breast cancer. Pathology, 41, 89-99.

Reed W, Hannisdal E, Boehler PJ, et al (2000). The prognostic value of $p 53$ and c-erb B-2 immunostaining is overrated for patients with lymph node negative breast carcinoma: a multivariate analysis of prognostic factors in 613 patients with a follow-up of 14-30 years. Cancer, 88, 804-13.

Sriplung H, Wiangnon S, Sontipong S, Sumatsawan Y, Martin M (2006). Cancer incidence trends in Thailand, 1989-2000. Asian Pac J Cancer Prev, 7, 118-25.

Singletary SE, Allred C, Ashley P, et al (2002). Revision of the American Joint Committee on Cancer staging system for breast cancer. J Clin Oncol, 20, 3628-36.

Taneja P, Maglic D, Kai F, et al (2010). Classical and Novel Prognostic Markers for Breast Cancer and their Clinical Significance. Clin Med Insights Oncol, 4, 15-34.

Woodward WA, Strom EA, Tucker SL, et al (2003). Changes in the 2003 American Joint Committee on Cancer staging for breast cancer dramatically affect stage-specific survival. $J$ Clin Oncol, 21, 3244-8.

Yu D, Hung MC (2000). Over-expression of ErbB2 in cancer and ErbB2-targeting strategies. Oncogene, 19, 6115-21.

Zhang H, Jin F (2010). HER-2 expression correlates with survivin in primary invasive ductal breast cancers. Asian Pac J Cancer Prev, 11, 1201-4. 